\title{
Riba Solutions Through Peer to Peer Lending Using Akad Qardhul Hasan
}

\author{
Marifah Yuliani ${ }^{1}$, Syarifuddin ${ }^{2}$, Sayugo Adi Puwanto ${ }^{3}$, Ira Indriani ${ }^{4}$, Merlin $\mathrm{D}^{5}$ \\ marifahyuliani@gmail.com¹, syarifstiem2018@gmail.com², sayugoadi@gmail.com³ \\ STIE Muhammadiyah Tanjung Redeb
}

\begin{abstract}
One sort of activity that contravene the principles of Islamic economics, which is violated today is the widespread practice of usury. Using smartphone as one of the advance technology enable for anyone to extend loans without collateral through financial technology (fintech) in the form of online loans. The amount of interest on online loans makes many people entangled with interest/usury because the people who initially could not be served by banks and industry financial institutions, through online loans can borrowed even without collateral. Though Islam since 1400 years ago has provided a solution to the problem of usury. That is the availability of a good loan or also known as qardhul hasan which is provides loans without interest, especially supported by peer to peer lending technology where a borrower only pays the principal and it is not burdened with administrative costs. Through peer to peer lending using the qardhul hasan contract can be a solution of the usury problem on community loans in financial institutions and online loans.
\end{abstract}

Keywords: Riba Solution, Peer to Peer Lending, Qardhul Hasan, Online Loan.

\section{Pendahuluan}

Kegiatan ekonomi modern berbasis teknologi yang paling banyak dimanfaatkan dewasa ini menggunakan ponsel pintar yakni financial technology (fintech), yang paling bermasalah dan berlawanan dengan syariat Islam adalah melakukan pinjaman berbasis online yang sangat mudah persyaratannya dan sangat cepat pencairan dananya, disebut pinjaman online (pinjol) baik yang mendapatkan izin resmi dari Otoritas Jasa Keuangan (OJK) maupun tidak, dengan menerapkan bunga (riba) yang sangat tinggi dan sangat memberatkan si peminjam.

Masifnya iklan di media sosial dan banyaknya SMS singkat yang disebar oleh aplikasi pinjaman online menjadikan masyarakat begitu mudah meminjam dengan syarat hanya berupa foto ktp dan beberapa syarat lain termasuk izin mengakses nomor kontak, gambar dan semacamnya. Dalam waktu satu jam rekening si peminjam sudah ditransfer uang pinjaman dari aplikasi pinjaman online. Sebuah kasus pinjaman online awalnya si peminjam melakukan peminjaman sebesar Rp 1.000.000,00 dengan bunga Rp 500.000,00 dan denda harian sebesar Rp 80.000,00 menyebabkan seseorang yang meminjam uang satu juta di pinjaman online di akhir bulan memiliki total utang sebesar Rp 3.900.000,00 [1]

Satu kasus lagi yang penulis temukan tersebar di media sosial facebook, yaitu seseorang melakukan pinjaman online sebesar Rp 4.000.000,00 (empat juta rupiah) pada bulan Mei 2018. Saat akhir tahun yakni di bulan Desember 2018 pinjaman yang bersangkutan sudah mencapai Rp 40.000.000,00 (empat puluh juta rupiah) dalam 7 bulan jumlah pinjaman menjadi sepuluh kali lipat dari pinjaman pokok. Dan pada bulan Juni 2019, jumlah pinjaman menjadi Rp 100.000.000,00 (seratus juta rupiah) dalam satu tahun satu bulan menjadi dua puluh lima kali 
lipat dibandingkan pinjaman pokok awal.[2] Padahal Islam sudah mengatur kegiatan muamalah di antara sesama manusia yang disebutkan dalam Alquran sebanyak lima kali, yakni pinjaman kebaikan (qardhul hasan). Berawal dari kasus tersebut di atas penulis ingin membahas solusi riba melalui pinjaman peer to peer menggunakan akad qardhul hasan.

\section{Metode}

Metode penelitian ini bersifat analisis deskripsi, yakni peneliti mengambarkan atau melakukan pemaparan atas subjek dan objek penelitian sebagaimana hasil penelitian yang dilakukan. [3] Berdasarkan sifat penelitian dan sumber data yang digunakan, artikel ini menggunakan metode penelitian kualitatif, yaitu prosedur penelitian yang menghasilkan data deskriptif berupa kata-kata tertulis atau lisan dari orang-orang dan perilaku yang dapat diamati. [4]

\section{Pembahasan}

\section{1. Riba}

Riba berasal dari kata raba yang berarti ziyadah (tambah) dan nama (tumbuh). Riba adalah tambahan (kelebihan) yang terjadi akibat proses pinjaman (baik uang maupun barang) yang ditentukan di awal akad maupun terjadi saat akad jatuh tempo (belakangan), dan umumnya berdasarkan persentase.

Padahal dalam fatwa Majelis Ulama Indonesia (MUI) No. 1 Tahun 2004 menyebutkan bahwa tambahan/bunga dalam transaksi pinjaman uang masuk kategori riba. Allah menyebutkan di dalam Alquran surah Al-Baqarah ayat 275 yang berbunyi "Padahal Allah menghalalkan jual beli dan mengharamkan riba". [5]

Adapun dosa riba sebagaimana dijelaskan Rasulullah bahwa Riba itu memiliki 73 tingkatan dengan dosa yang paling ringan seperti seseorang yang berzina dengan ibu kandungnya sendiri, dari hadits ini kita pahami bahwa riba memiliki banyak cabang, bahkan sampai 73 tingkatan atau jenisnya dan dosanya sangat besar di akhirat kelak. Benarlah di zaman sekarang, aplikasi riba itu banyak dan bahkan sebagian umat Islam masih mencari penghidupan dari riba padahal satu dirham riba (kurang lebih Rp.70.000,- tahun 2020) dosanya di sisi Allah lebih dari 33 kali dosa berzina (HR. Thabrany) dan Rasulullah melaknat orang yang mengambil riba (kelebihan atas pinjaman), melaknat orang yang membayar riba (orang yang berhutang), juru tulis (akuntan, teller, dan pegawai administrasi), saksi-saksi (notaris, satpam, cleaning service, kontraktor, dan semua pihak lain yang terlibat di dalam bisnis riba).

\section{2. Qardhul hasan}

Besarnya dosa riba dan mudahnya akses riba dewasa ini diperlukan kajian yang bisa mengatasi fenomena riba di masyarakat, yakni dengan mengembalikan ketentuan Allah melalui qardhul hasan. Qardhul hasan adalah pemberian harta kepada orang lain yang dapat ditagih atau diminta kembali atau dengan kata lain meminjamkan tanpa mengharapkan imbalan. Qardhul hasan merupakan pinjaman kebajikan yang tidak bersifat komersial, tetapi bersifat sosial. [6] Qardhul hasan berarti pinjaman yang baik, yaitu mengembalikan pinjaman sesuai jumlah yang dipinjam dengan ikhlas tanpa syarat sebelumya. [7]

Qardhul hasan merupakan pinjaman yang sangat dianjurkan dalam Islam. Islam merupakan agama yang sangat Indah. Setiap kebaikan atau kegiatan tolong menolong, tidak 
boleh membebani pihak yang membutuhkan. Tidak boleh mengambil keuntungan di atas penderitaan atau kebutuhan orang yang sangat terdesak. Oleh karenanya setiap akad pinjaman tidak boleh ada kelebihan pembayaran, hal ni bertujuan agar setiap orang yang memiliki kelebihan rezeki tidak mendzolimi orang lain yang kekurangan. Tidak boleh ada eksploitasi atas pihak yang mengalami kekurangan. Sehingga orang yang berhutang hanya wajib membayar pokoknya saja.

Qardhul hasan merupakan pinjaman yang bersifat lunak yang sangat bermanfaat kepada masyarakat yang kurang mampu dan juga masyarakat mampu. Qardhul hasan bukan akad yang boleh mendapatkan manfaat, melainkan murni bertujuan tolong menolong (tabarru'). Penerapan qardhul hasan bisa antara orang-perorang, orang dengan lembaga maupun antara lembaga dengan lembaga lainnya. Dalam Alquran disebutkan sebanyak 5 kali yaitu dalam sûrat Al Hadid ayat 11, [8] sûrat Ath-Thagabun ayat 17, [9] sûrat al-Muzzammil ayat 20, sûrat Al-Baqarah ayat 45, dan sûrat Al-Maidah ayat 12.

Bukan hanya Alquran yang menyebutkan qardhul hasan (pinjaman kebaikan), Hadits Nabi Muhammad juga ada mengenai keutamaan memberikan pinjaman kepada sesama manusia yakni pada saat Rasulullah shallallahu 'alaihi wasallam melakukan perjalanan isra mi'raj, Rasulullah shallallahu 'alaihi wasallam melihat tulisan di atas pintu surga yang berbunyi, 'Sedekah akan dikalikan menjadi sepuluh kali lipat, dan memberi pinjaman dengan delapan belas kali lipat'. Hal ini menjadikan keutamaan dalam Islam untuk memberikan pinjaman kebaikan lebih besar pahala dan manfaat yang diterima kedua belah pihak (baik penerima pinjaman maupun orang yang memberikan pinjaman, dengan syarat tidak boleh ada kelebihan) dibandingkan dengan memberikan sedekah.

Dalam HR. Ibnu Majah disebutkan bahwa pinjaman seorang muslim sebanyak dua kali melainkan seperti dia telah bersedekah satu kali. Artinya bahwa dalam pinjaman seseorang mendapatkan pahala yang banyak termasuk pahala sedekah.

Berdasarkan lima ayat Alquran dan dua hadits di atas hendaknya umat Islam kembali kepada mengamalkan ajaran meminjamkan uang kepada sesama karena riba memiliki efek uang berputar diantara para pemilik modal saja, sedangkan pinjaman dan dalam hal lain yakni sedekah akan memutar uang di masyarakat sehingga uang beredar di lapisan masyarakat bukan hanya di kalangan pemilik modal.

Adapun salah satu dampak dari riba yang dirasakan masyarakat adalah adanya kenaikan harga yang disebut dengan inflasi. Inflasi atau kenaikan harga dibandingkan masa sebelumnya terjadi salah satunya akibat adanya riba di sebuah negara. Negara yang menerapkan suku bunga pinjaman maka setiap tahunnya akan mengalami kenaikan harga secara terus-menerus. Hal ini disebabkan Bank Sentral yang menerapkan suku bunga. Kemudia masyarakat yang meminjam wajib membayar lebih bunga yang dikenakan terhadap mereka. Sehingga uang yang beredar di masyarakat setiap tahun selalu meningkat dan menyebabkan inflasi di masyarakat.

Salah satu bentuk indahnya Islam yang menerapkan pinjaman kebaikan dan keharaman riba (kelebihan pinjaman) maka menyebabkan harga seekor kambing dari zaman Rasulullah shallallahu 'alaihi wasallam 1400 tahun yang lalu sampai sekarang tetaplah bernilai 1 dinar (kurang lebih 3 juta rupiah di tahun 2020). Begitu juga harga seekor ayam sejak zaman Rasulullah shallallahu 'alaihi wasallam 1400 tahun yang lalu sampai sekarang masih bernilai 1 dirham (kurang lebih 70 ribu rupiah tahun 2020). Hal ini merata di semua negara, artinya dinar dan dirham dari dulu tidak pernah mengalami inflasi, sedangkan semua mata uang di dunia mengalami inflasi.

3. 3. Peer to Peer Lending

Peer to Peer (P2P) dalam bahasa Inggris kalau diterjemahkan artinya dari "ujung" ke “ujung". [10] P2P (peer-to-peer) lending adalah penyelenggaraan layanan jasa keuangan untuk 
mempertemukan pemberi pinjaman dengan penerima pinjaman dalam rangka melakukan perjanjian pinjam meminjam melalui sistem eletronik dengan menggunakan jaringan internet. Layanan P2P merupakan penyelenggara badan hukum Indonesia yang menyediakan, mengelola dan mengoperasikan Layanan Pinjam Meminjam Uang Berbasis Teknologi Informasi. Peraturan P2P diatur dalam Peraturan Otoritas Jasa Keuangan (POJK). [11]

Peer to peer lending merupakan bagian dari fintech dan di Indonesia sudah terdapat beberapa fintech syariah yang berbeda dengan fintech konvensional. Terdapat tiga prinsip yang tidak boleh ada di fintech syariah yakni maysir (judi), gharar (ketidakpastian) dan riba (kelebihan/bunga). Namun belum ditemukan adanya akad qardhul hasan yang digunakan karena fintech syariah yang ada didirikan memiliki tujuan keuntungan (profit oriented) berbeda dengan akad qardhul hasan yang termasuk pada tujuan kebaikan, yakni tolong menolong (tabarru').

3. 4. Aplikasi Peer to Peer Lending Menggunakan Akad Qardhul hasan

Implementasi peer to peer lending menggunakan akad qardhul hasan yang paling baik bukan hanya tidak adanya bunga atau tambahan (baik itu berupa uang ataupun manfaat) atas pinjaman, juga diterapkannya bebas biaya administrasi, dan tanpa denda. Kalau memang diperlukan, bisa menggunakan agunan yang tidak boleh melanggar hukum syariah. Dalam penerapannya tentu diperlukan sebuah start up yang tidak berorientasi laba atau keuntungan, baik si pengelola aplikasi maupun si pemilik dana tidak berharap untung di dunia, melainkan ingin membantu sesama dengan berharap rida Allah semata. Oleh karena itu diperlukan dukungan dana yang tidak murah dalam pengembangannya. Peer to peer lending menggunakan akad qardhul hasan juga bisa diterapan secara offline, bisa melibatkan para pengurus masjid dan para pengusaha serta orang kaya di lingkungan masjid tersebut. Yang diperlukan adalah sosialisasi ekonomi Islam ini ke pengusaha kaya (agar mampu memberikan dana yang bisa disalurkan sebagai dana pinjaman ke masyarakat menjadi dana bergulir), pengurus masjid (bisa digunakan dana sebagian masjid yang tidak mengganggu operasional masjid untuk menyelamatkan penduduk sekitar masjid dari riba) dan masyarakat yang ingin terlibat baik sebagai pemberi pinjaman maupun sebagai peminjam. Untuk pengelola kegiatan ini, para pengurus bisa digaji oleh dana masjid atau para relawan yang amanah yang mau untuk tidak digaji karena barang siapa yang menolong agama Allah maka Allah langsung yang akan menolongnya.Untuk itu, apabila sudah berjalan, maka yang didahulukan para peminjam yang terlilit riba dan untuk kebutuhan pokok/pendidikan, bukan riba yang diambil dari keinginan seperti membeli mobil atau liburan. Diutamakan orang yang ingin bebas dari riba, rentenir dan pinjaman online terlebih dahulu, kalau dana sudah besar, bisa digunakan untuk modal usaha.

3. 5. Solusi Menghindari Kredit Macet

Permasalahan yang paling besar atas adanya pinjaman qardhul hasan yang selama ini penulis amati adalah banyaknya kredit macet. Hal ini dikarenakan tidak adanya jaminan dan kelebihan, serta sebagian mental masyarakat yang mudah berjanji, tetapi sulit untuk menepati sehingga tidak melunasi pinjaman yang telah diberikan. Padahal bagi si pemilik dana, tentu uang yang dipinjamkannya melalui pinjaman peer to peer menggunakan akad qardhul hasan ini bertujuan agar bisa dimanfaatkan orang banyak sehingga diperlukan solusi untuk mengatasi kredit macet. Beberapa alternatif solusi tersebut, sebagai berikut:

a. Diawali saat membuat akad, adanya penegasan mengenai bahaya tidak melunasi hutang, berdasarkan hadits Rasulullah shallallahu 'alaihi wasallam bahwa memperlambat membayar pinjaman bagi orang yang memiliki harta adalah suatu kezaliman. (Muttafaqun'alaih). Dan siapa yang meminjam dengan niat tidak ingin membayar pinjamannya maka kelak di akhirat dia akan bertemu Allah sebagai pencuri. (HR. Ibnu Majah dan Baihaqi)

b. Berdasarkan ayat terpanjang dalam Surah Albaqarah yaitu ayat 282, menyebutkan bahwa dalam setiap utang-piutang hendaknya dituliskan dengan benar dan dihadirkan saksi 
sebanyak 2 orang laki-laki atau 1 orang laki-laki dan 2 orang perempuan. Hal ini bertujuan agar orang yang berutang bertanggung jawab dan untuk saling mengingatkan serta si pemberi utang memiliki bukti berupa saksi, jikalau yang menerima utang menjadi ingkar janji.

c. Untuk peminjam yang bekerja sebagai Pegawai Ngeri Sipil (PNS) atau karyawan swasta yang memiliki gaji tetap maka memungkinkan diadakannya potong gaji si peminjam setiap awal bulan. Hal ini tentunya harus disepakati dulu antara pelaksana peer to peer landing dengan perusahaan atau kantor si peminjam.

d. Untuk pelaku usaha yang termasuk usaha kecil menengah (UKM), solusi pembayaran angsuran pinjaman kebaikan bisa menggunakan pembayaran mingguan bahkan harian. pembayaran harian terkesan murah dan ringan dibandingkan pembayaran bulanan karena angka yang lebih ringan maka akan mengurangi beban mereka yang meminjam. Tentu ini merupakan solusi dibandingkan UKM yang meminjam kepada rentenir atau lintah darat, mereka juga menerapkan sistem pembayaran harian atau mingguan, bahkan menerapkan bunga yang besar.

e. Solusi untuk membuat jera peminjam yang mengulur-ulur waktu pembayaran dengan sengaja adalah dengan mengadakan pengumuman utang di masjid sekitar tempat tinggal si peminjam. Hal ini tentunya sudah atas sepengetahuan si peminjam (dimasukkan di akad dan disetujui si peminjam), yang setelah beberapa lama jatuh tempo masih belum bayar, dan sudah diketahui bahwa yang bersangkutan memang mampu tetapi sengaja tidak membayar. Dengan demikian seseorang akan berpikir ulang untuk tidak melunasi utangnya karena tentunya akan malu diumumkan di masjid dekat tempat tinggalnya bahwa dia memiliki utang kepada orang lain. Hal ini tentu lebih baik dari pada hal yang dilakukan pinjaman online dewasa ini melalui bahasa yang mengancam dan tidak sopan/santun via pesan singkat, juga terjadinya teror kepada keluarga, teman dan rekan kerja peminjam karena si operator pinjaman online mendapatkan data semua kontak yang didapat saat pemimjam ingin berutang.

Urgennya pinjaman qardhul hasan bagi masyarakat adalah karena maraknya riba di masyarakat, hal ini dikarenakan ekonomi kita menggunakan sistem kapitalis dan liberalis, hanya menguntungkan para pemilik modal dan melepaskan agama dari kegiatan ekonomi sehari-hari. Selain itu, kendala dalam penerapan qardhul hasan di masyarakat karena sudah menipisnya kejujuran dan kepercayaan kepada sesama akibat keuntungan material (dunia) semata yang ingin diraih. Umat harus dikembalikan kepada ajaran agama, bahwa hal-hal yang dimiliki sekarang di dunia tidak bisa membantu menyelamatkannya kelak di hari pembalasan. Oleh karena itu perlu wadah aplikasi yang tidak hanya bertujuan keuntungan duniawi sementara, melainkan juga berinvestasi untuk hari kemudian. Diperlukan modal yang tidak sedikit untuk ini, oleh karena itu elemen pengusaha, para pemilik start up, tokoh agama, akademisi, dan pemerintah untuk duduk bersama dan bisa mengatasi permasalahan riba yang berat ini.

\section{Kesimpulan}

Seiring dengan berkembangnya teknologi industri 4.0 dewasa ini banyak masyarakat yang terjebak dengan pinjaman online (pinjol) dengan bunga (riba) sangat tinggi dan merugikan masyarakat padahal teknologi juga bisa digunakan untuk menerapkan perintah Allah yakni dengan adanya pinjaman nol persen (akad qardhul hasan) dan tanpa biaya administrasi melalui aplikasi pinjaman peer to peer (peer to peer lending).

\section{References}


[1] Awan Gunawan, Ditelpon $\quad$ Pinjol, dalam https://m.facebook.com/story.php?story_fbid=10214869665200720\&id=1399711851\&ref=content_filter (2019)

[2] Anonim, dalam https://m.facebook.com/photo.php?fbid=308746140079243\&id=100028315786707\&set=gm.5612 91-154402984\&source $=48$ (2019)

[3] Mukti Fajar Nur Dewata dan Yulianto Ahmad, Dualisme Penelitian Hukum Normatif dan Empiris, Yogyakarta, Pustaka Pelajar, h. 183 (2010)

[4] Nurul Zuriah, Metodologi Penelitian Sosial dan Pendidikan: Teori-Aplikasi, Jakarta: Bumi Aksara, 2007 h. 92 (2007)

[5] Fatwa Majelis Ulama Indonesia No. 1 Tahun 2004 tentang Bunga (Interest/Fa'idah).

[6] Ascaraya, Akad dan Produk Bank Syariah, Jakarta, PT Raja Grafindo Persada, h.46 (2008)

[7] M. Abdul Mujieb, dkk, Kamus Istilah Fiqih, Jakarta: Pustaka Firdaus, h. 272 (1994)

[8] Firdaus Furywardhana, Mudah Memahami Ekonomi Islam, Yogyakarta: Kamajaya Kreasindo, h. 33 (2009)

[9] Burhanuddin S., Hukum Perbankan Syariah di Indonesia, Yogyakarta: UI Press, h. 280 (2008)

[10] Wikipedia, P2P, dalam https://id.m.wikipedia.org/wiki/P2P

[11] Sulfiati,dkk, 2010. Akuntabilitas Pengelolaan Dana Bantuan Operasional Sekolah (BOS) Dalam Penyelenggaraan Pendidikan Di KabupatenSinjai, Jurnal Ilmu Pemerintahan, Vol.3, No.2 Juli 2010. 